\title{
Student Teachers' Views of the impact of School Experience Programme on their Perceptions of the Teaching Profession
}

\author{
T.D. Mushoriwa \\ M.P. Mavuso \\ Faculty of Education, University of Fort Hare (Alice Campus), East London, South Africa \\ Tmushoriwa@ufh.ac.za; pmavuso@ufh.ac.za
}

\section{Doi:10.5901/mjss.2014.v5n8p336}

\begin{abstract}
This study analysed the impact of the School Experience (SE) programme on rural student teachers' perceptions of the teaching profession. This was done through investigating the views of Post Graduate Certificate in Education (PGCE) and Bachelor of Education (BEd) fourth year students which were randomly selected. A qualitative and quantitative survey through semi- structured questionnaire with closed and open - ended items and structured interviews was conducted. The majority of student teachers (86\%) felt that school experience positively socialised them into the teaching profession by providing them with the needed work-based experience. Most of the student teachers in the study felt that a student teacher's experiences during SE mediate their beliefs, opinions, views and convictions about the teaching profession, making them like or dislike the profession. Ten percent were ambivalent and still an insignificant number (4\%) decided against the teaching profession. One of the major recommendations of the study is that since the SE programme is critical in the formation of one's perceptions about and commitment to the teaching profession, teacher training institutions should design appropriate SE programmes and closely monitor them to ensure they continue achieving the intended goals.
\end{abstract}

Keywords: impact, institutions, monitor, perceptions, rural student teachers, socialise, social participation, school experience, teaching profession, teaching practice.

\section{Introduction}

The poor registration by student passing Grade-12 in the early 2000s became a great concern to the then Minister of Education Kader Asmal and this resulted in him announcing a teacher recruitment campaign in 2004 (Douglas, 2005). The decline in the interest of teaching profession was firstly caused among other things by natural attrition and HIVIAIDS pandemic, and replacement strategy and new measure to make teaching attractive were not adequate (Ibid, 2005). Secondly, few students were not registering to pursue studies in the teaching profession (The Mercury, 2004). Lastly, many newly qualified teachers were seeking work in other countries or were migrating to other sectors (Wasserman, 2003). Furthermore, the decline in the desirability of teaching has been exacerbated by poor conditions in many schools, new policies that place extra demands on teachers, and media reports blaming teachers for poor examination results due to lack of professionalism (Douglas, 2005). In the late 1990s, there had been a complete closure of teacher colleges and this put more pressure on universities to produce teachers. This means therefore that institution of higher learning /universities had to intensify their School Experience (SE) programmes as they became the sole producers of teachers who were diminishing in the system due to the above stated reasons.

The present study therefore explored the impact of the SE /teaching practice on rural student teachers' perceptions of the teaching profession with a view to improving future SE for student teachers. It is important to study the impact of the SE programme on the teachers' perceptions of the teaching profession because while SE is a learning and development opportunity, it may result in some student teachers developing negative attitudes towards the teaching profession. It must be noted that although research on the SE programme has been done in many institutions, no such study has been done at Fort Hare. So, while the present study might appear a replication of studies done elsewhere, it is significant in that it provides a basis for comparison with what goes on in other institutions and this is likely to improve the design and the execution of student teachers' SE programmes in the institutions of higher learning.

It was hoped that a study of this nature might detect flaws in the way students' SE is conducted by institutions in order to ensure that SE achieves its intended goals such as fully inducting student teachers into the profession. Furthermore, the assumption was that the improved SE programmes by teaching institutions may bring about good 
quality teachers who will make significant contribution to the attainment of quality learners' education outcomes. This means that, when properly planned and properly implemented, as it was presumed, SE programmes may assist in the problem of teacher morale and thereby improving the quality of teaching and learning in schools. Directly or indirectly the enhanced quality of teaching and learning would contribute positively to the global economic growth and that of South Africa in particular. This means therefore that the production of good quality teachers is in way an endeavour towards economic development of a particular country and of the world in general.

A study by Chikunda (2005) in Zimbabwe found that some student teachers develop fear and anxiety during SE because of some lecturers who came to find faults, allocate marks and leave without discussing with the student what was wrong and right with the lesson. Such practices can result in student teachers not enjoying their internship and might have serious unintended outcomes. Teaching practice is "learning activity involving the process of social participation whereby the impact of the situation (experiences) is fundamental" (Tuimur, Role\& Makewa, 2012:236). This indicates that the student teachers' experiences during the SE programme has far-reaching effects on their overall view of the profession.

\subsection{Background and literature review}

At the university of Fort Hare, Alice Campus, where this study was conducted, both PGCE and B Ed students go on SE for 10 weeks. Usually SE starts in July and ends in September. This period was well conceived of given that, largely, it does not coincide with exams/tests in schools. Class teachers see exam/test times as critical for their learners and they would be unwilling to leave student teachers take their classes. Once in schools, student teachers are given a week to establish themselves in their schools before supervision and assessment by lecturers begins. It is during this first week that these student teachers are attached to qualified teachers teaching the same subjects (mentors). When lecturers begin to visit these student teachers, the policy is that they must inform the student teachers about the visit in a day or two in advance. Failure to do this may result in the student teacher refusing to be observed. For Frohlich \& le Roux (2004), such practices result in school experience being a process of allocating marks rather than of learning. Perhaps by that, the students are admitting that they are not always fully prepared for the lessons, If this happens which they are still in training one wonders what happens when they have completed.

While a number of studies (e.g Chikunda, 2005; Wambugu, Barmao \&Ngeno, 2013) have focused on student teachers' perceptions of teaching practice, very few, to the authors' knowledge, have focused on the influence or impact of school experience on student teachers' perceptions of the teaching profession. Kiggunda \& Nayimbi (2009) conducted a study on how teaching practice influences the perceptions of student teachers regarding the teaching profession but their study, conducted at Vaal University of Technology in Gauteng, focused on urban and not on rural student teachers as is the case in the present study. Rurality was a variable of interest and therefore a point of departure to the present writers given the often adverse teaching and learning conditions often found in rural schools. Also the present study could not have come at a better time than now when media reports (e.g. Sunday Times, November 10, 2013:12) indicate that large numbers of pupils are abandoning Eastern Cape (South Africa) public schools because of the poor quality of education in the province. Reasons given range from, among others, the collapse of management and governance structures to poor and /or under - qualified teachers. The present writers assumed that student participants in this study, after going through their SE programme in such schools and under such teachers, might have developed negative attitudes towards the teaching profession. Teachers have a critical role to play in any country's development and prosperity. Competent teachers almost guarantee the realisation of the expected and appropriate outcomes. For Almagableh (2010), a well trained teacher is capable of teaching effectively, taking into account, pupils' social, cultural and individual differences. "If teaching practice is executed rightly and effectively, it will assist in producing high quality professionally- qualified teachers" (Wambugu, Barmao \&Ngeno, 2013:171). To the present writers, any attempt to improve an education system should start with how teachers are trained. The quality of the training has a direct bearing on the quality of the teacher and hence, the quality of the education given. It is against this backdrop that the present study was instituted to find out student teachers' views on the impact of the SE programme on their perceptions of the teaching profession.

\subsection{Objective of the study}

The objective of the study was to establish the impact of the school experience programme on student teachers' perceptions of the teaching profession. 


\section{Methodology}

\subsection{Research design}

The survey research design was employed in this study. Surveys are appropriate not only for large samples, but also for collecting peoples' views, opinions, and perceptions etc on a particular issue at a particular point in time. Thus, surveys can be used to determine and evaluate people's attitudes and practices in order to improve them. The present study intended to determine student teachers' perceptions of the teaching profession after going through SE programme in order to see how these perceptions can be improved if necessary.

\subsection{Sample and Sampling}

Seventy (70) students (females=60\%; mean age=25.6 years $\mathrm{SD}=1.9$ ) randomly recruited from the PGCE and $B$ Ed students who had just gone through their SE programme participated in this study. The study deliberately ignored sampling by both programme (i.e. PGCE and BEd) and Subject Area of specialisation because some studies (see Tuimur, Role \& Makewa, 201; Wambugu, Barmao \& Ngeno, 2013) have already focused on these variables in their study of student teachers' perceptions of teaching practice.

\subsection{Instruments}

Sixty $(n=60)$ participants responded to a semi-structured questionnaire which required the participants to provide demographic data (gender, age) and to respond to closed and open- ended items. Open -ended items allowed the students to express their views as much as possible but of course within the confines of the research design. The fact that the questionnaires were anonymous added to the frankness of the responses. In some cases, participants were required to give reasons for their answer(s). This permitted an in-depth analysis of the results.

Ten $(n=10)$ participants responded to structured interviews only which were conducted at the same time with the administration of the questionnaires. These interviews complemented the questionnaires and were therefore useful in checking the credibility of information collected. .The writers also conducted some follow-up interviews with 20 students who had responded to the questionnaires to probe into subtle and obscure issues which had been raised in the questionnaire responses.

\subsection{Validity and reliability of instruments}

The questionnaire, developed by the investigators, was given to four experts in the field of study to see if it measured what it was intended to measure (validity). There was unanimity among the experts regarding the suitability and appropriateness of the questionnaire.

For reliability, the experts were also asked to rate the questionnaire (out of 10). These ratings were correlated and an inter-rater reliability coefficient of 0,73 was yielded, indicating that to a large extent, the raters agreed that the questionnaire was reliable.

The questionnaire was then piloted with a group of ten(10) students to check if the wording was accessible. After minor modifications, the questionnaire was adopted for use with the sample of the study ( $n=60$ ).

\subsection{Ethical Considerations}

After seeking permission from the Faculty of Education authorities, the participating students were approached as a group. They were requested to participate in the study if they so wished. Sixty students volunteered to complete the anonymous 16- item questionnaire while 10 students volunteered to be interviewed.

\section{Results and Discussion}

As already seen, the study set out to establish the impact of school experience on rural student teachers' perceptions of the teaching profession. The results are presented according to the questionnaire items, with interview responses allowing in-depth analysis of the results.

Item 1 required the participants to indicate what influenced them to choose the teaching profession. Sixty six 
percent $(n=40)$ of the student teachers indicated that they had joined the profession out of interest in the profession, $27 \%$ $(n=16)$ gave varied reasons such as respect and dignity associated with the profession, the ease of finding a job, influence from family members etc while the remaining $7 \%(n=4)$ indicated that they had joined the profession by defaultthey had nowhere else to go so they joined the profession while waiting for other career opportunities. These results are not unique to student teachers at Fort Hare (Alice Campus). Kiggundu \& Mayimuli (2009) made similar observations among PGCE students at Vaal University of Technology (South Africa) where some students saw the profession as a stopgap while they waited for better career opportunities. Perhaps it is such teachers who eventually lack commitment to the profession if they do not change such attitudes.

Eighty-one percent $(n=49)$ of the student teachers indicated that they were mentally/psychologically ready for the school experience before going to the SE (item 2). Such psychological readiness is essential for developing positive attitudes towards one's work given that SE has been reported to cause a lot of anxiety, tension and apprehension among many student teachers (Manion, Keith, Morrison \& Cohen, 2003; Chikunda, 2005). Given that SE can be a very frightening experience for some students, psychological readiness can cushion these fearful students, creating confidence in them. Confidence in one's work has been found to be one of the major variables influencing a teacher's effectiveness in the classroom (Martin, Linfoot \&Stephenson, 1999; Gialls \& Little, 2003). This means therefore that institutions of higher learning should emphasize on the preparatory stage of SE as it is crucial for adjusting student teachers emotions, making them ready for the experience in the school situation. This may in turn help enhance the attainment of learners' educational goals.

Item 3 required the student teachers to indicate what they liked most about the SE programme. Frequent responses were: controlling and managing learners, tasting the richness, complexity and diversity of the teaching and learning environment, translating theoretical knowledge and skills into classroom learning, discovering my teaching strengths and weaknesses. Put together, these responses almost summarise the goals/ aims/ objectives of the SE programme. One student teacher interviewed commented:

The recent school experience programme allowed me to assess whether I had made the right career choice. I enjoyed it, so I think I am cut out to be a teacher.

Such comments do not only indicate the success of the SE programme, but also its impact on student teachers' perceptions of the teaching profession. For Chen \& Mu (2010), teacher training cannot be complete without an effective practicum programme where student teachers go into schools and classrooms and face the realities there. A teacher requires practice in using the skills involved in teaching before teaching in the real classroom context ( Wambugu, Barmao \& Ng'eno, 2013). To the present writers, while the SE programme is basically meant to provide students teachers with an opportunity to put their knowledge and skills into practice before they start to work as professionals (Bhargara \& Pathy, 2011), it ends up influencing positively or negatively, the student teachers' views about the teaching profession.

In item 4, the student teachers were asked to indicate what they disliked most about the SE programme. Sixty five percent $(n=39)$ complained about large class sizes with pupils of diverse abilities. This made it difficult for the student teachers to maintain order and to individualise their instruction. Twenty-eight percent $(n=17)$ were not happy with the issue of text books which many schools lacked, $5 \%(n=3)$ complained about some mentors who did not allow them to observe their lessons while an insignificant two percent $(n=1)$ complained about schools that set up environments that do not foster learning. Responses to item 11 also showed that many student teachers $(67 \%, n=40)$ were worried about poor discipline in some schools, resulting in many pupils lacking commitment to their school work. Though there was no significant number of student teachers who indicated that SE programme had impacted negatively on their perception of the teaching profession,these challenges may in the long run, to a certain extent, have detrimental effect on their perception of the teaching profession. Furthermore, in relation to the the challenges faced by student teachers during SE programme, Kiggundu and Nayimuli (2009) argue that the effectiveness of teaching practice can be diminished or eroded if these challenges are not addressed

One interviewee commented:

It was a bit challenging because I found some teachers not qualifying to teach the learning areas they were teaching and this created a situation where I had to be tasked to teach other classes that I was not supposed to teach during school experience. Another thing is that teachers were in most cases not willing to give me space to teach as they indicated that they were behind schedule. In some cases, you would find a principal favouring one teacher or a group of teachers. This results in teachers fighting as those who are not favoured develop negative attitudes. This actually helped me as I now understand the dynamics in schools with regard to relations. 
It can be seen from this excerpt that when student teachers embark on the SE programme, they do not only learn how to teach and deal with learners but they also become socialised into the teaching profession itself as they are exposed to staff relationships and staffroom politics. In this regard, Gijjar, Naoreen, Saifi \& Bajwa (2010) argue that, teaching practice provides opportunity to beginning teachers to become socialized into the profession as they become able to predict their future success and their dealings in the teaching profession.

Comments by supervisors (item 5) and by mentors (item 8) were seen as very useful. Furthermore, comments by different supervisors and from supervisors and mentors did not contradict each other. This suggests that there is an agreement on what is expected of student teachers. This uniformity in the supervision and assessment of the student teachers can largely be attributed to the use of a Supervision Form which stipulates areas to be looked at.

Eighty-four percent $(n=50)$ of the student teachers felt that the duration of the SE programme (10 weeks) was adequate (item 13). It allowed them to practise teaching sufficiently and to be seen enough by the supervisors (at least twice in each subject area as required). However, both interview data and responses to item 7 revealed that most students prefer being seen by different supervisors not only by one to avoid being disadvantaged by 'the strict' supervisor but also to benefit from the enriching effect of different ideas from different supervisors. One student teacher commented:

I prefer being seen by different supervisors because while some supervisors are heartless when it comes to marks, others are fairly generous - so a combination of the two is ideal.

Item 12 required the student teachers to indicate whether, given a second chance to go on SE, they would prefer to go back to the same schools. Seventy-five percent $(n=45)$ indicated they would want to go back to the same schools, giving reasons such as warm reception, good discipline in the schools, support and cooperation from staff members, good resources in the schools etc. Twenty-five percent $(n=15)$ felt that they would want to change schools, citing cold reception and relationships in the school which made them feel unwelcome, poor discipline, inadequate resources etc. This shows that student teachers expect schools to help and support them to grow and develop during their internship.

Eighty-eight percent ( $n=53)$ indicated that overall, they found their school experience useful and positively contributing to their professionalism (item 14). This suggests the success of the SE programme at Fort Hare as perceived by the student teachers themselves. However, two major suggestions to improve the SE programme were made (Item 15). The first suggestion, which came from $51 \%(n=31)$ of the student teachers was that supervisors should take their time with the student teacher both before and after the supervision. Thus, there is need for pre- and post- conference with the student teacher.

Literature (e.g. Nyaume, 2001; Chikunda, 2005) stresses the importance of both pre- and post- supervision conferences with student teachers. Pre- supervision conferences help to get the student teacher settle down before conducting the lesson. One interviewee noted:

Being observed is a disturbing and uncomforting experience for most of us; we need time to cool down yet some supervisors start by dragging us into the classroom and criticise us for being nervous or for lacking confidence.

Post- supervision conferences involve discussions where the student teacher is also given time to defend why he/she did things the way he/she did them. Such procedures enrich future lesson delivery because the student teacher comes to understand why certain things should be done or should not be done. SE ceases to be a process of allocating marks but a process of the student teachers' growth and development.

In an interview, one student teacher lamented: Some supervisors have no time for us. They give marks and rush to the next school without even consulting our mentors. This is embarrassing; mentors begin to wonder why they should waste their time with us. Wailer, Gadzirayi \& Mukondo (2002:59) made similar observations when they wrote about "lecturers in a hurry" who do not have time for both student teachers and mentors. Perhaps this is why Chikunda (2005) says that many supervisors tend to downplay their tutorial role and accentuate their assessment role- this defeats the real purpose of SE.

For Nyaume (2001: 241), "in an ideal situation, mentors and university tutors have equal contributions to the knowledge student teachers need". For Chikunda (2005: 271), mentors are major players in the training of one of their own but lecturers usually ignore them when they visit their student teachers" Indeed this is regrettable. Supervisors should first meet the mentors to find out how the student teacher is progressing and hear about the challenges facing the student teacher; yet in most cases this does not happen.

In recognising the importance of the role of the mentor, one interviewee noted: At least one mark awarded by the mentor should count towards the student teacher's final mark. In institutions or countries where mentors are well serviced, this is already happening .In the writers' view, adopting a supervision model that puts mentors into place but 
fails to recognise their contribution is self-defeating.

The second suggestion (Item 15) which came from only $16 \%(n=10)$ was that supervisors should not inform student teachers about their visits. One interviewee commented: Knowing in advance that supervisors are coming results in some student teachers teaching the lessons in advance; supervisors only come to see staged lessons. These sentiments echo practices in many institutions where supervisors' visits are not announced. This ensures that student teachers are fully prepared for all lessons all the time. This helps to give student teachers the right impression about the teaching profession.

The last item (Item 16) required the student teachers to indicate whether, after their school experience, they would say that they have chosen the right profession. This item was meant to see whether, overall, the SE programme had positively impacted on the student teachers' perceptions of the teaching profession. An overwhelming majority (86\%; $\mathrm{n}=52$ ) indicated that they felt that they had chosen the right profession. This suggests that the SE programme positively impacted on the student teachers' perceptions of the teaching profession. Ten percent $(n=6)$ were undecided while $4 \%$ $(n=2)$ indicated that their experience during the SE programme had made them dislike the teaching profession. When asked how he perceived school experience in relation to his choice of the teaching profession, one student teacher responded:

There is a lot that should be done for students as they do not get enough resources like books and computers. However, that has not changed my love for the teaching profession. Instead ,it has given me more insight into the challenges that are facing educators and learners.

This could be an indication that when some student teachers choose the teaching profession, they do so from intrinsic motives and are perhaps driven by a will to make change in the education system. This may be an indication that they see themselves as agents of change when they assume duties of full time educators.

When asked how school has experience helped in boosting her inspiration of becoming a teacher, one participant commented:

\begin{abstract}
It helped me because I got different kinds of attitudes and experiences and that has helped me in boosting my aspirations to become a teacher. It helped me to gain confidence as I became exposed to how to deal with learners in the classroom. It also helped me because it allowed me an opportunity to share with other teachers who are already in the field.
\end{abstract}

This was an indication that SE plays a very important role in the life of teachers- in - the-making as they are exposed to real life situations of their chosen profession. It is during this time that they taste their profession. Manion, Keith, Morrison \& Cohen (2003) noted that, teaching practice is a very important transition in the process of teacher training as it creates a mixture of anticipation, anxiety, excitement and apprehension in the student teachers.

In the present study, the majority of student teachers (86\%; $n=52)$ involved in the study reported positive perceptions towards the teaching profession presumably because of their experiences during their SE programme. If these results are accepted, then one is justified to conclude that the SE programme at Fort Hare is succeeding not only in preparing student teachers for teaching but also for imparting positive professional attitudes, making the student teachers like their profession.

While there are conflicting views on the impact of SE on student teachers' perceptions of the teaching profession the fact that the majority reported positive perceptions towards teaching practice may be an indication that SE play a critical role in the training of educators even in rural context. The findings are thus important in designing the Se programmes in the institutions of higher learning. Though the findings to large extent indicate that SE programme impact positively on student teachers' perceptions of the teaching profession, there is still a room for improvement particularly in institutions that are located in rural communities. This means that any framework for the implementation of SE programmes should take into consideration the rural nature of some institutions.

Based on the observations made in study, two major recommendations are made:

- Since student teachers' experiences during the school experience programme impact on their attitudes and perceptions towards the teaching profession, teacher training institutions should not only design appropriate school experience programmes but should also constantly and closely monitor them to ensure that they continue to achieve the intended goals.

- Teacher training institutions that use the mentor model should increasingly give mentors a more active role in the training of student teachers and should be empowered through workshops. 


\section{References}

Al- magableh, AMF 2010. An evaluation of English practicum at Yormuk University from cooperative and student teachers' perceptions. International Journal of Language Studies, 4(4): 263-300.

Bhargara A \& Pathy M 2011. Perceptions of student teachers about teaching Competencies. American International Journal of contemporary Research, 1(1): 77-81.

Chen J \& Mu Z 2010. The cross- national comparison of pre-service Mathematics Teacher Education and curriculum structure. Journal of Mathematics Education, $3(1): 119-136$.

Chikunda C 2005. An analysis of challenges and learning opportunities surrounding college-based teaching practice supervision: The case of Mature Teachers' College. Zimbabwe Journal of Education Research, 17(3):258-274.

Douglas J 2005.Transformation of the South African schooling system: Teacher Professionalism and Education Transformation. The Centre for Education Policy Development, 1-34.

Frohlich GL \& le Roux C 2004. Supporting tutoring within Namibian Environmental Education Course. Southern African Journal of Environmental Education, 21:120-133.

Giallo R \& Little E 2003. Classroom behaviour problems: The relationship between preparedness, classroom experience and self efficacy in graduate and student teachers. Australian Journal of Educational Developmental Psychology, 3: 21-34.

Gujjar AA, Naoreen B, Saifi S \& Bajwa MJ 2010. Teaching Practice: Issues and Problems in Parkistan. International Online Journal of Educational Sciences, 2 (2): 339-361.

Kiggundu E \& Nayimuli S 2009. Teaching practice: A make or break phase for Student teachers. South African Journal of Education, 29: 245-258.

Manion L, Keith RB, Morrison K \& Cohen L 2003. A guide on teaching practice. Available at http://wwwbooks.google.com/books. Accessed 06 January 2014.

Martin A, Linfoot K \& Stephenson J 1999. How teachers respond to concerns about misbehaviour in the classroom. Psychology in schools, 36:347- 358.

The Mercury, 2004. KZN Heading for Teacher Shortage, 31 May.

Nyaumwe, L 2001. A Survey of Barunda Unversity of Science Education student teachers' perceptions of the mentoring model of teaching practice. Zimbabwe Journal of Education Research, 13(3): 230-252.

Sunday Times 2013. Pupils flee under par Eastern Cape schools, November 10 pp.12.

Tuimur R, Role E \& Makewa LN 2012. Evaluation of student teachers grouped according to teaching subjects: Students perceptions. International Journal of Education, 4(4): 232-246.

Wailer J, Gadzirayi C \& Mukondo I 2002. Teaching practice supervision: A need for new model. Zimbabwe Bulletin of Teacher Education, 11(2): 53-65.

Wambungu P, Barmao A \& Ng'eno J 2013. Student teachers' perceptions of teaching practice assessment in Egerton Unversity, Kenya. Education Journal, 2(4): 169-175.

Wasserman J 2003. Unpublished data from questionnaires completed by third-year B.Ed. students at Edgewood Campus, University of Natal. 